\title{
Horner syndrome secondary to Hodgkin lymphoma
}

\author{
Andrew Micieli MD, Zeina Ghorab MD, Jonathan A. Micieli MD CM
}

Cite as: CMAJ 2020 February 24;192:E187. doi: 10.1503/cmaj.190910

A previously healthy 31-year-old woman presented to the ophthalmology clinic with a 2-month history of left ptosis. She also reported a dry cough, non-exertional dyspnea and anhidrosis on the left side of her face. On examination, her vital signs were normal, and she had mild left ptosis and anisocoria, which was worse in dim lighting conditions, with a smaller left pupil (Figure 1A). The patient was also found to have bulkiness throughout the left cervical and supraclavicular area, diminished breath sounds and dullness to percussion on the left. Computed tomography of the chest showed a large left anterior mediastinal mass with extension into the left supraclavicular region and left upper lobe (Figure 1B). The appearance of the mass was highly suggestive of a lymphoproliferative disease, and biopsy confirmed the diagnosis of Hodgkin lymphoma (Appendix 1, available at www.cmaj.ca/lookup/suppl/ doi:10.1503/cmaj.190910/-/DC1). The patient received treatment with ABVD (Adriamycin [doxorubicin], bleomycin, vinblastine and dacarbazine) chemotherapy and radiation (1000 cGy in 5 fractions) to the mediastinum, resulting in disease remission. At an 18-month follow-up, the left ptosis and anisocoria remained stable.

Horner syndrome, also known as oculosympathetic paresis, is a result of disruption of the sympathetic pathway that begins in the hypothalamus and takes a long course down the spinal cord to C8-T2, courses around the apex of the lung and ascends with the internal carotid artery before entering the orbit. ${ }^{1}$ Any patient with signs of Horner syndrome, including ptosis, miosis and anhidrosis, should have a thorough history and physical examination looking for associated neurologic signs, neck or respiratory symptoms, and orbital signs to help localize the lesion. This patient had prominent respiratory symptoms and signs, which were confirmed with imaging. Mediastinal lymphoma is a rare cause of Horner syndrome, but should be kept in the differential diagnosis because the respiratory symptoms may be absent or subtle. ${ }^{2,3}$ Imaging of the entire sympathetic pathway is recommended when no obvious cause is demonstrated from the history and physical examination. ${ }^{1}$

\section{References}

1. Reede DL, Garcon E, Smoker WR, et al. Horner's syndrome: clinical and radiographic evaluation. Neuroimaging Clin N Am 2008;18:369-85.

2. Simon SR, Dorighi JA, Branda RF, et al. Horner's syndrome: an unusual presentation of Hodgkin's disease. Med Pediatr Oncol 1985;13:390-1.

3. Ruiz E Resende LS, Gaiolla RD, Niéro-Melo L, et al. Post-ganglionic Horner's syndrome: an unusual presentation of non-Hodgkin's lymphoma. Case Rep Neurol 2012;4:43-6.
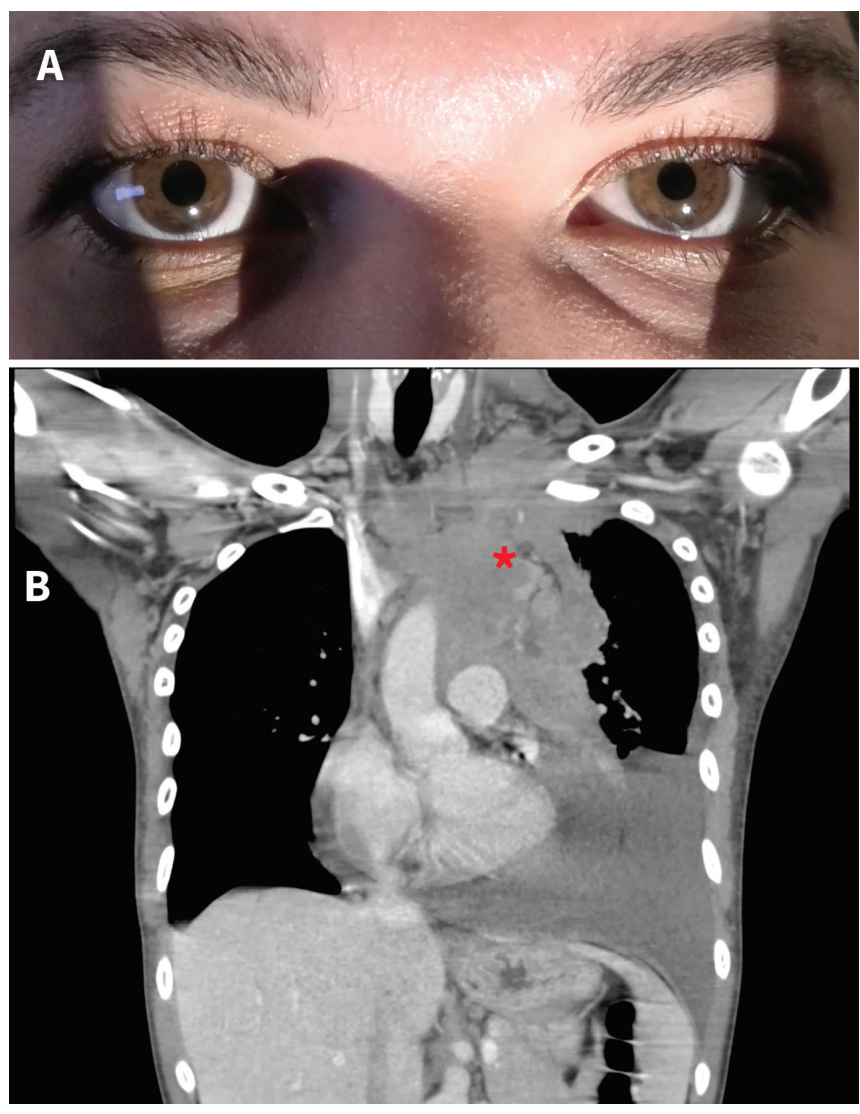

Figure 1: (A) Photograph showing left mild ptosis and miosis in a 31-yearold woman. (B) Computed tomography scan of the chest showing a large left mediastinal mass $\left({ }^{*}\right)$ with extension into the left supraclavicular region and left upper lobe.

\section{Competing interests: None declared.}

This article has been peer reviewed.

The authors have obtained patient consent.

Affiliations: Division of Neurology (A. Micieli, J. Micieli), Department of Medicine, University of Toronto; Department of Laboratory Medicine and Molecular Diagnostics (Ghorab), Sunnybrook Health Sciences Centre, and Department of Ophthalmology and Vision Sciences (J. Micieli), University of Toronto; Kensington Vision and Research Centre (J. Micieli), Toronto, Ont.

Correspondence to: Jonathan Micieli, jonathanmicieli@gmail.com 